\title{
A retrospective study of extracolonic, non-endometrial cancer in Swedish Lynch syndrome families
}

\author{
Masoud Karimi ${ }^{1}$, Jenny von Salomé ${ }^{2,3}$, Christos Aravidis ${ }^{4}$, Gustav Silander $^{5}$, Marie Stenmark Askmalm ${ }^{6,8}$, \\ Isabelle Henriksson ${ }^{7,8}$, Samuel Gebre-Medhin ${ }^{7,8}$, Jan-Erik Frödin ${ }^{1}$, Erik Björck ${ }^{2,3}$, Kristina Lagerstedt-Robinson ${ }^{2,3}$, \\ Annika Lindblom ${ }^{2,3}$ and Emma Tham ${ }^{2,3^{*}}$ (D)
}

\begin{abstract}
Background: Lynch Syndrome is an autosomal dominant cancer syndrome caused by pathogenic germ-line variants in one of the DNA-mismatch-repair (MMR) genes MLH1, MSH2, MSH6 or PMS2. Carriers are predisposed to colorectal and endometrial cancer, but also other cancer types. The purpose of this retrospective study was to characterize the tumour spectrum of the Swedish Lynch syndrome families.

Methods: Data were obtained from genetically verified 235 Lynch families from five of the six health care regions in Sweden. The material was stratified for gender, primary cancer, age and mutated gene and the relative proportions of specific cancer types were compared to those in the general population.

Results: A total of 1053 family members had 1493 cancer diagnoses of which 1011 were colorectal or endometrial cancer. Individuals with pathogenic variants in MLH1 and MSH2 comprised 78\% of the cohort. Among the 482 noncolorectal/non-endometrial cancer diagnoses, MSH2 carriers demonstrated a significantly increased proportion of urinary tract, gastric, small bowel, ovarian and non-melanoma skin cancer compared to the normal population. MLH1 carriers had an elevated proportion of gastrointestinal cancers (gastric, small bowel, pancreas), while MSH6 carriers had more ovarian cancer than expected. Gastric cancer was predominantly noted in older generations.
\end{abstract}

Conclusion: Lynch syndrome confers an increased risk for multiple cancers other than colorectal and endometrial cancer. The proportions of other cancers vary between different MMR genes, with highest frequency in MSH2-carriers. Gender and age also affect the tumour spectrum, demonstrating the importance of additional environmental and constitutional parameters in determining the predisposition for different cancer types.

Keywords: Lynch syndrome, MMR genes, Tumour spectrum, Extracolonic

\section{Background}

Lynch syndrome (LS) is an inherited autosomal dominant condition predisposing mainly to colorectal and endometrial cancer [1]. In addition, individuals with LS are at increased risk for developing malignancies other than colorectal and endometrial cancer, mostly cancer of the gastrointestinal tract, but also ovarian, urothelial and brain tumours have been reported to occur more often

\footnotetext{
* Correspondence: Emma.Tham@ki.se; emma.tham@sll.se

${ }^{2}$ Department of Clinical Genetics, Karolinska University Hospital, Solna, 17176 Stockholm, Sweden

${ }^{3}$ Department of Molecular Medicine and Surgery, Karolinska Institutet,

Stockholm, Sweden

Full list of author information is available at the end of the article
}

than in the general population [2-5]. LS is caused by pathogenic germ-line variants in DNA-Mismatch-Repair (MMR) genes, MLH1, MSH2, MSH6 or PMS2 [6] and the tumour spectrum is influenced mostly by the affected gene and gender $[4,5,7]$. Most pathogenic variants (80\%) are reported in $M L H 1$ and $M S H 2$, which might reflect differences in expression between different pathogenic MMR variants, such as later age at onset of disease and reduced penetrance suggested in MSH6 and PMS2 [1, 2, 7, 8].

LS should be suspected in patients with an age onset of colorectal cancer before 50 years, proximal localisation of colorectal cancer, high DNA microsatellite

(C) The Author(s). 2018 Open Access This article is distributed under the terms of the Creative Commons Attribution 4.0 International License (http://creativecommons.org/licenses/by/4.0/), which permits unrestricted use, distribution, and 
instability in histological specimen of colorectal cancer, multiple primary meta/synchronous polyps/tumours in colon, rectum and endometrium, endometrial cancer before 50 years of age, or a familial clustering of cancer diagnoses, using criteria such as Amsterdam II or Bethesda guidelines $[9,10]$. Surveillance for colorectal cancer has been shown to increase survival in LS [11]. It is not yet clear if surveillance for other cancer types associated with LS would be beneficial in all patients. More knowledge about the phenotypical manifestation of different pathogenic variants in LS is required to improve the surveillance programs for different LS families. We therefore characterised the spectrum of tumours in the Swedish Lynch syndrome families and calculated the relative proportion of non-colorectal/non-endometrial cancers to further support their association to Lynch syndrome.

\section{Methods}

The study was approved by the Regional Ethical Review Board in Stockholm, Sweden. In Sweden, patients with a family history suggestive of LS are generally referred for genetic counselling to a department of clinical genetics at six university hospitals that provide regional genetic services with family investigations, genetic testing and recommendations for surveillance. For our study, five of six nationwide genetic centres in Stockholm, Uppsala, Umeå, Linköping and Lund (covering 83\% of Swedish population, i.e. 8.3 million individuals) agreed to participate, providing us with anonymous full pedigree information. The information regarding cancer diagnosis, age at onset, or date of death were confirmed by medical reports or death certificates when available with the written consent from the affected relative, or (if deceased) from the closest relatives. All pedigrees harboured at least 3 consecutive generations and contained information about gender, type of gene variant, birth date, age at cancer diagnosis, cancer according to the ICD7 classification, tumour site and age at death and the status of pedigrees has been updated as of December 2014.

Patients with early onset LS spectrum early onset cancer, synchronous or metachronous cancer, or Amsterdam II and/or Bethesda criteria fulfilled were genetically tested for LS. Genetic screening of the affected family members was performed in most cases using mainly Sanger DNA sequencing or otherwise massive parallel sequencing. The sequencing analyses were combined with multiplex ligation-dependent probe amplification (MLPA, P003 and P072; MRC-Holland, Amsterdam, The Netherlands) for the detection of large deletions or duplications.

\section{Statistics}

Statistical analyses included family members with a proven pathogenic germ-line variant, obligate carriers, individuals with a $50 \%$ risk of having a pathogenic variant, or combinations thereof. Obligate carrier status was allocated to members due to their position in the pedigree in relation to relatives with known pathogenic variants or other obligate carriers. First degree relatives to proven or obligate carriers who had not been tested for the familial variant were assigned a 50\% carrier probability. These 265 individuals with cancer increased the number of tumours in the analysis, but due to a potential risk of error as their genetic status was unknown, we redid the analysis only including those individuals with known genetic status with similar results (data not shown).

Analysis of the relative proportions of cancer diagnoses was performed as previously described [12]. The age at cancer diagnosis was known, but we did not have data on the year of birth or diagnosis of cancers in our observed data and could thus not calculate cumulative incidence. Therefore, the tumour distribution in the relatives of index patients is compared with the cancer distribution in the Swedish population at two time points, 1970 and 2010 (Swedish Cancer Registry). The population distribution of cancer was weighted by the age and sex of cases in the data (relatives to index cases). Cases where age or sex was missing were assumed to have the same age and sex distribution as cases where age and sex were known. We analysed each gene separately as well as each gender in the entire cohort.

\section{Results}

In total, we obtained pedigrees from 235 families with Lynch syndrome (MLH1 $n=97, M S H 2 n=87, M S H 6 n=$ 37 and PMS2 $n=14$ ). In 1053 family members, at least one cancer diagnosis was identified (Table 1). Of these, 445 (42\%) individuals had a proven pathogenic variant, 343 (33\%) were obligate carriers and 265 (25\%) individuals were assigned a $50 \%$ carrier probability. Table 1 summarizes the clinical characteristics and genetic status of the patients. In total, 1493 cancer diagnoses were found in our study cohort, of which $90 \%$ were verified using the cancer registry or medical records. Information on age at cancer diagnosis was available in $90 \%$ of patients. A total of 647 first-time colorectal cancers (if metachronous

Table 1 Lynch syndrome family members distributed by gene and gender

\begin{tabular}{llll}
\hline & Male & Female & Total \\
& $\mathrm{n}(\%)$ & $\mathrm{n}(\%)$ & $\mathrm{n}(\%)$ \\
\hline MLH1 & $231(22)$ & $201(19)$ & $432(41)$ \\
MSH2 & $194(18)$ & $195(19)$ & $389(37)$ \\
MSH6 & $69(7)$ & $122(12)$ & $191(18)$ \\
PMS2 & $25(2)$ & $16(2)$ & $41(4)$ \\
Total & $519(49)$ & $534(51)$ & $1053(100)$ \\
\hline
\end{tabular}


cancers were included the total was 795) and 203 cases of first-time endometrial cancer (216 including metachronous) were registered, corresponding to $43 \%$ and $14 \%$ of all reported cancer cases in the cohort, respectively (Table 2). Colorectal cancer represented $64 \%$ of all cancer in men and in $36 \%$ in women, while endometrial cancer represented $28 \%$ of all cancer in women (Table 2). A total of 482 cancers were non-colorectal, non-endometrial cancer. To calculate the relative proportion of these less common cancer diagnoses in the study cohort, all cases of colorectal and endometrial cancer were excluded from further analysis.

Compared to the general population, individuals of both sexes in the cohort as a whole had a higher proportion of gastric cancer (Tables 3 and 4). Gastric cancer was more frequent in male than female mutation carriers and tended to be present in older generations as only 6/67 cases in the cohort were born after 1940 (Table 2; data not shown). The relative proportion of small bowel cancer was also elevated in both men and women with Lynch syndrome and the mean age at onset was on average 4 years younger than for gastric cancer (Tables 2, 3 and 4). Females had an increased proportion of ovarian cancer, but also of non-melanoma skin cancer, the latter was not increased in men (Tables 3 and 4). While the proportion of urinary tract cancer was significantly elevated in females in the cohort, this was only true in males with a $100 \%$ probability of carrying a pathogenic MMR variant (data not shown). Prostate and breast cancer were common in male and female Lynch syndrome carriers respectively, but the proportion was not elevated compared to the general population, indeed, the proportion of breast cancer was lower than expected among our Lynch syndrome cohort).

Of note, most of the extracolonic, non-endometrial malignancies occurred as single cases in the kindred. A few families demonstrated multiple individuals with the same cancer, e.g. in one family there were four cases of gastric cancer and two families had four cases of ovarian cancer. Breast cancer also clustered in a few families (Table 5).

As the spectrum of LS associated tumours is influenced by the genetic composition of the cohorts, we stratified the study population according to mutated MMR gene. We could not analyse PMS2 carriers, as the number of cases with non-colorectal/non-endometrial cancers $(n=7)$ was too low for further analysis.

\section{MLH1}

MLH1 carriers had an elevated frequency of gastric, pancreas and small bowel but not of skin, urinary tract or ovarian cancer (Table 6). The mean age at diagnosis for all these cancers in our $M L H 1$ cohort was a few years younger than the average age in the population (Swedish Cancer Registry).

\section{MSH2}

Carriers of pathogenic variants in $\mathrm{MSH} 2$ carriers had an elevated proportion of several cancers including urinary tract, gastric, non-melanoma skin, ovarian and small bowel cancer (Table 7). The MSH2 carriers diagnosed with urinary tract and ovarian cancer showed a greater proportion with onset before age of 50 years in comparison with MLH1 carriers (Table 9). In fact, $64 \%$ of ovarian cancers in the entire cohort were diagnosed before the age of 50 years. (Table 8 ) and $25 \%$ had an onset before the age of 40 years among all carriers with this especially true for $\mathrm{MSH} 2$ carriers where $34 \%$ were diagnosed before 40 years (data not shown). Of note, the elevated proportion of non-melanoma skin cancer found in $\mathrm{MSH} 2$ carriers (Table 7) was reflected in the female but not the male MMR carrier group (Tables 3 and 4).

\section{MSH6}

In the group with pathogenic variants in $\mathrm{MSH6}$, ovarian cancer was noted in around $11.5 \%$ versus $4 \%$ in the MLH1 group (Tables 6 and 9). The proportion of gastric cancer in MSH6 carriers was higher than normal in the general population but the difference was not statistically significant (Table 9). Of 8 cases of gastric cancer in the MSH6 cohort, the age at diagnosis could be confirmed for 6 and 4 of these (67\%) occurred before age of 50 years (Table 8 ).

The number of affected individuals with small bowel cancer $(n=0)$, skin cancer $(n=1)$ and urinary tract cancer $(n=10)$ was too limited for analysis in the MSH6 group.

\section{Discussion}

This is the first retrospective analysis of the phenotype of the Swedish LS families ascertained by the Departments of Clinical Genetics across the nation. The spectrum of pathogenic MMR variants in Swedish families has been previously reported [13] and this study further explores the tumour spectrum of the Swedish Lynch syndrome families.

It is well established that carriers of heterozygous pathogenic variants in MLH1, MSH2, MSH6 and PMS2 have an increased risk of colorectal and endometrial cancer and that the four MMR genes demonstrate different penetrance and expressivity [2-5]. In order to determine the relative frequency of the less common cancers in the Swedish LS population, we stratified our cohort by mutated MMR gene and gender and excluded colorectal cancer and endometrial cancer from the statistical analysis. 


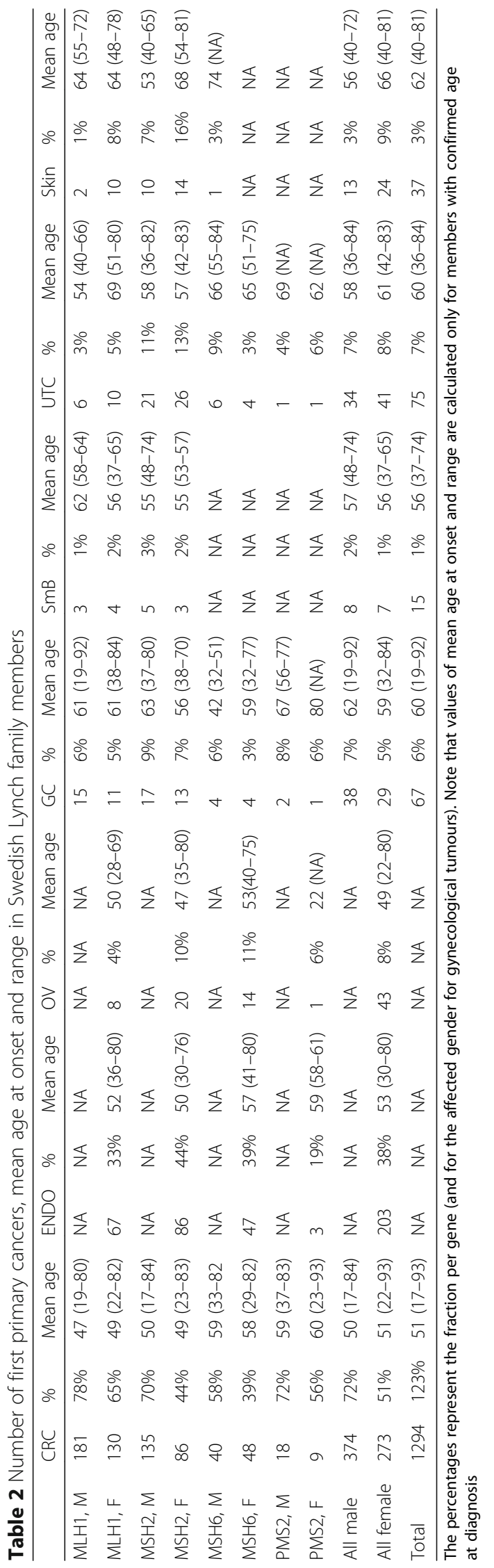


Table 3 Observed cancer cases for the male Lynch syndrome cohort with 100\% or 50\% probability of MMR mutation (excluding colorectal and endometrial cancer)

\begin{tabular}{|c|c|c|c|c|c|c|c|}
\hline Primary cancer & $\begin{array}{l}\text { Observed } \\
\text { number }\end{array}$ & $\begin{array}{l}\text { Proportion } \\
{[\%]}\end{array}$ & $\begin{array}{l}\mathrm{LL} \\
95 \%\end{array}$ & $\begin{array}{l}\text { UL } \\
95 \%\end{array}$ & $\begin{array}{l}\text { Proportion [\%] } \\
\text { in Sweden } 1970\end{array}$ & $\begin{array}{l}\text { Proportion [\%] } \\
\text { in Sweden } 2010\end{array}$ & $\begin{array}{l}\text { Reference } \\
\text { outside Cl }\end{array}$ \\
\hline Stomach & 38 & 18.36 & 13.04 & 23.67 & 8.84 & 1.76 & above \\
\hline Prostate & 38 & 18.36 & 13.04 & 23.67 & 10.82 & 26.47 & No \\
\hline Kidney and urinary tract excl prostate & 34 & 16.43 & 11.59 & 21.74 & 13.05 & 8.75 & No \\
\hline Brain and nervous system & 19 & 9.18 & 5.31 & 13.04 & 7.94 & 5.66 & No \\
\hline Skin excl melanoma & 13 & 6.28 & 3.38 & 9.66 & 2.44 & 5.24 & No \\
\hline Pancreas & 12 & 5.8 & 2.9 & 9.18 & 3.36 & 1.74 & No \\
\hline Malignant melanom & 9 & 4.35 & 1.93 & 7.25 & 5.19 & 10.35 & No \\
\hline Blood and lymphatic tissue & 9 & 4.35 & 1.93 & 7.25 & 12.53 & 12.3 & below \\
\hline Small bowel & 7 & 3.38 & 0.97 & 5.8 & 0.75 & 0.77 & above \\
\hline Liver and biliary system & 6 & 2.9 & 0.97 & 5.31 & 2.44 & 2.04 & No \\
\hline Lung and airways & 5 & 2.42 & 0.48 & 4.83 & 11.38 & 5.51 & below \\
\hline Oesophagus & 4 & 1.93 & 0.48 & 3.86 & 1.22 & 0.93 & No \\
\hline Head and neck & 3 & 1.45 & 0 & 3.38 & 5.76 & 4.04 & below \\
\hline Bone and soft tissue & 3 & 1.45 & 0 & 3.38 & 2.1 & 1.52 & No \\
\hline Testicle & 2 & 0.97 & 0 & 2.42 & 3.43 & 6.54 & below \\
\hline Breast & 1 & 0.48 & 0 & 1.45 & 0.33 & 0.28 & No \\
\hline Penis & 1 & 0.48 & 0 & 1.45 & 0.66 & 0.37 & No \\
\hline Thyroid & 1 & 0.48 & 0 & 1.45 & 1.13 & 1.37 & No \\
\hline Eye & 0 & 0 & 0 & 0 & 0.58 & 0.44 & below \\
\hline Endocrine cancer & 0 & 0 & 0 & 0 & 2.57 & 1.91 & below \\
\hline Unspecified location & 0 & 0 & 0 & 0 & 3.45 & 2.01 & below \\
\hline
\end{tabular}

The observed proportions adjusted for age and sex are compared to those of the general population in year 1970 and 2010 (ref National Board of Health and Welfare). If the observed confidence interval in the Lynch syndrome group did not overlap with the proportions in the general population, the reference is denoted as "above" (or "below") the reference

LL Lower level of $95 \%$ confidence interval, UL upper level of $95 \%$ confidence interval

\section{Gastric cancer}

Both male and female carriers overall and both $M L H 1$ and $M S H 2$-carriers had an increased proportion of gastric cancer, which was not seen in MSH6-carriers. A recent prospective study including 3119 Lynch syndrome patients demonstrated a cumulative risk for gastric cancer of $7.1 / 7.7 \%$ in $M L H 1 / M S H 2$ carriers and $5.3 \%$ in MSH6 carriers [7]. Of interest, other studies have shown a preponderance of male gastric cancer [35] which was also the case among our Lynch syndrome cases. According to the Swedish cancer registry, a clear decrease in annual incidence and relative proportion for gastric cancer in the general population has been observed: from 5,4\% in 1970 to $1,22 \%$ in 2010. Barrow et al. showed a decreasing incidence of gastric cancer in Lynch families and fewer than $10 \%$ of the Lynch syndrome carriers born after 1935 developed gastric cancer [3]. A similar finding could also be noted in our cohort with only 6/67 cases with gastric cancer born after 1940 . This relatively low incidence of gastric cancer in later Lynch generations raises the issue of the value of screening gastroscopy in Lynch families, especially as most cases occurred as single sporadic cases within families. The clinical benefit of screening Lynch patients with gastroscopy probably exists for a very limited group, but the yield is likely too small to be cost-effective.

\section{Small bowel cancer}

Small bowel cancer is a rarity, representing $0.5 \%$ of cancer cases in Sweden 2010, while the cumulative lifetime risk in the LS group has been estimated to be between $0.6-7 \%[4,5]$. The significantly increased proportion for of small bowel cancer in our LS in our cohort was evenly distributed between both sexes with similar risks for MLH1 and MSH2 carriers. No cases of small bowel cancer were observed in MSH6 carriers. A recently published prospective Dutch study examined the eventual benefit of capsule endoscopy (the recommended surveillance procedure) in 200 asymptomatic LS family members. No cases of small bowel cancer could be detected in the study group during the 2-year surveillance [14]. Recently updated guidelines from the Mallorca group (2013) do not recommend any screening for small bowel cancer [15]. Based on these studies, our data and the 
Table 4 Observed cancer cases for the female Lynch syndrome cohort with 100\% or 50\% probability of MMR mutation (excluding colorectal and endometrial cancer)

\begin{tabular}{|c|c|c|c|c|c|c|c|}
\hline Primary cancer & $\begin{array}{l}\text { Observed } \\
\text { number }\end{array}$ & $\begin{array}{l}\text { Proportion } \\
{[\%]}\end{array}$ & $\begin{array}{l}\mathrm{LL} \\
95 \%\end{array}$ & $\begin{array}{l}\text { UL } \\
95 \%\end{array}$ & $\begin{array}{l}\text { Proportion [\%] } \\
\text { in Sweden } 1970\end{array}$ & $\begin{array}{l}\text { Proportion [\%] } \\
\text { in Sweden } 2010\end{array}$ & $\begin{array}{l}\text { Reference } \\
\text { outside C }\end{array}$ \\
\hline Breast & 58 & 21.17 & 16.42 & 26.28 & 31.79 & 43.61 & below \\
\hline Ovary and Fallopian tube & 42 & 15.33 & 11.31 & 19.71 & 9.51 & 3.8 & above \\
\hline Kidney/urinary tract excl prostate & 41 & 14.96 & 10.95 & 19.34 & 5.25 & 3.34 & above \\
\hline Stomach & 29 & 10.58 & 6.93 & 14.23 & 4.47 & 1.11 & above \\
\hline Skin excluding melanoma & 24 & 8.76 & 5.47 & 12.41 & 1.37 & 4.4 & above \\
\hline Cervix & 20 & 7.3 & 4.38 & 10.58 & 10.72 & 3.71 & No \\
\hline Brain and nervous system & 12 & 4.38 & 2.19 & 6.93 & 4.58 & 4.5 & No \\
\hline Blood and lymphatic tissue & 11 & 4.01 & 1.82 & 6.57 & 7.45 & 6.81 & below \\
\hline Small bowel & 8 & 2.92 & 1.09 & 5.11 & 0.38 & 0.4 & above \\
\hline Liver and biliary system & 7 & 2.55 & 0.73 & 4.74 & 2.87 & 1.34 & No \\
\hline Lung and airways & 5 & 1.82 & 0.36 & 3.65 & 3.03 & 5.95 & No \\
\hline Pancreas & 4 & 1.46 & 0.36 & 2.92 & 2.38 & 1.58 & No \\
\hline Malignant melanoma & 4 & 1.46 & 0.36 & 2.92 & 3.8 & 8.63 & below \\
\hline Thyroid & 3 & 1.09 & 0 & 2.55 & 2.01 & 2.59 & No \\
\hline Oesophagus & 2 & 0.73 & 0 & 1.82 & 0.37 & 0.31 & No \\
\hline Bone and soft tissue & 2 & 0.73 & 0 & 1.82 & 1.16 & 0.71 & No \\
\hline Head and neck & 1 & 0.36 & 0 & 1.09 & 1.68 & 1.92 & below \\
\hline Endocrine cancer & 1 & 0.36 & 0 & 1.09 & 2.44 & 2.09 & below \\
\hline
\end{tabular}

The observed proportions adjusted for age and sex are compared to those of the general population in year 1970 and 2010 (ref National Board of Health and Welfare). If the observed confidence interval in the Lynch syndrome group did not overlap with the proportions in the general population, the reference is denoted as "above" the reference

LL Lower level of $95 \%$ confidence interval, UL upper level of $95 \%$ confidence interval

rarity of this diagnosis, a routine screening for detection of small bowel cancer is questionable.

\section{Ovarian cancer}

The cumulative lifetime risk for ovarian cancer in LS is reported to be between 7 and $24 \%$ up to age 70 years and varies between genotypes, with most older studies reporting the highest risks in $M S H 2$ and $M L H 1$ carriers, as the number of families with pathogenic variants in MSH6 have been too low in most studies for conclusive results $[4,16]$. Newer studies including MSH6 carriers indicate a $10-13 \%$ cumulative risk for ovarian cancer, comparable to that of $\mathrm{MSH} 2$ carriers and perhaps higher than the risk for $M L H 1$ carriers $[5,7]$. This was also seen in our cohort with the $M S H 2$ and MSH6 carriers demonstrating an increased frequency of ovarian cancer, while the $M L H 1$ carriers did not. A striking observation in our study was the high proportion of ovarian cancer before the age of 50 years in mutation carriers: $80 \%$ for $M S H 2,63 \%$ for $M L H 1$ and $42 \%$ for MSH6 (Table 9). Similar results have been noted by Helder-Woolderink and co-workers in their systematic review of ovarian cancer in LS family members where $29 \%$ of the cases had an onset before the age of 35 years [17].

Screening for gynaecological cancer has not proven to be effective in detecting pre-malignant lesions [18-20], even though single individuals with precursor cystic lesions have been detected at an early stage [21]. Results from a recently published multicentre prospective study of surveillance performed on 1942 MLH1and MSH2 carriers without previous cancer, also point to the unsatisfying efficacy of gynaecological screening as precursor lesions were seldomly found in the endometrium or

Table 5 Intrafamilial clustering of some common cancers in Swedish Lynch syndrome families

\begin{tabular}{|c|c|c|c|c|c|}
\hline & 1 case/family & 2 case/family & 3case/family & 4 case/family & 5 case/family \\
\hline Gastric cancer & $58(87 \%)$ & $5(7.5 \%)$ & $3(4 \%)$ & $1(1.5 \%)$ & 0 \\
\hline Brain tumour & $25(81 \%)$ & $6(19 \%)$ & 0 & 0 & 0 \\
\hline Urinary tract cancer & $61(81 \%)$ & $9(12 \%)$ & $5(7 \%)$ & 0 & 0 \\
\hline Ovarian cancer & $37(86 \%)$ & $3(7 \%)$ & $1(2 \%)$ & $2(5 \%)$ & 0 \\
\hline
\end{tabular}

Number of families with multiple cases of the specified tumour and percent of the total 
Table 6 Observed cancer cases for the MLH1 cohort with 100\% or 50\% probability of MMR mutation (excluding colorectal and endometrial cancer)

\begin{tabular}{|c|c|c|c|c|c|c|c|}
\hline Primary site & $\begin{array}{l}\text { Observed } \\
\text { number }\end{array}$ & $\begin{array}{l}\text { Proportion } \\
\text { [\%] }\end{array}$ & $\begin{array}{l}\mathrm{LL} \\
95 \%\end{array}$ & $\begin{array}{l}\mathrm{UL} \\
95 \%\end{array}$ & $\begin{array}{l}\text { Proportion [\%] } \\
\text { in Sweden } 1970\end{array}$ & $\begin{array}{l}\text { Proportion [\%] } \\
\text { in Sweden } 2010\end{array}$ & $\begin{array}{l}\text { Reference } \\
\text { outside Cl }\end{array}$ \\
\hline Breast & 28 & 17.72 & 12.03 & 24.05 & 16.61 & 23.02 & No \\
\hline Stomach & 26 & 16.46 & 10.76 & 22.15 & 6.31 & 1.4 & above \\
\hline Kidney/urinary tract excl prostate & 16 & 10.13 & 5.7 & 15.19 & 8.99 & 5.77 & No \\
\hline Skin excl melanoma & 12 & 7.59 & 3.8 & 12.03 & 1.76 & 4.5 & No \\
\hline Pancreas & 11 & 6.96 & 3.16 & 11.39 & 2.66 & 1.6 & above \\
\hline Brain and nervous system & 10 & 6.33 & 2.53 & 10.13 & 6.61 & 5.34 & No \\
\hline Ovary and Fallopian tube & 8 & 5.06 & 1.9 & 8.86 & 4.97 & 2.02 & No \\
\hline Small bowel & 7 & 4.43 & 1.27 & 7.59 & 0.57 & 0.57 & above \\
\hline Liver and biliary system & 6 & 3.8 & 1.27 & 6.96 & 2.52 & 1.65 & No \\
\hline Malignant melanoma & 6 & 3.8 & 1.27 & 6.96 & 4.98 & 10.18 & No \\
\hline Cervix & 5 & 3.16 & 0.63 & 6.33 & 5.79 & 2.08 & No \\
\hline Prostate & 5 & 3.16 & 0.63 & 6.33 & 4.26 & 11.02 & No \\
\hline Head and neck & 4 & 2.53 & 0.63 & 5.06 & 3.69 & 2.95 & No \\
\hline Lung and airways & 4 & 2.53 & 0.63 & 5.06 & 6.79 & 5.46 & below \\
\hline Oesophagus & 3 & 1.9 & 0 & 4.43 & 0.74 & 0.58 & No \\
\hline Blood and lymphatic tissue & 3 & 1.9 & 0 & 4.43 & 10.02 & 9.72 & below \\
\hline Bone and soft tissue & 2 & 1.27 & 0 & 3.16 & 1.75 & 1.17 & No \\
\hline Testicle & 1 & 0.63 & 0 & 1.9 & 1.98 & 3.65 & below \\
\hline Thyroid & 1 & 0.63 & 0 & 1.9 & 1.68 & 2.22 & No \\
\hline Female genital organ & 0 & 0 & 0 & 0 & 0.54 & 0.33 & below \\
\hline Penis & 0 & 0 & 0 & 0 & 0.32 & 0.18 & below \\
\hline Eye & 0 & 0 & 0 & 0 & 0.48 & 0.35 & below \\
\hline Endocrine cancer & 0 & 0 & 0 & 0 & 2.66 & 2.12 & below \\
\hline Unspecified location & 0 & 0 & 0 & 0 & 3.32 & 2.14 & below \\
\hline
\end{tabular}

The observed proportions adjusted for age and sex are compared to those of the general population in year 1970 and 2010 (ref National Board of Health and Welfare). If the observed confidence interval in the Lynch syndrome group did not overlap with the proportions in the general population, the reference is denoted as "above" the reference and is marked in bold

LL Lower level of $95 \%$ confidence interval, UL upper level of $95 \%$ confidence interval

ovaries [8]. At least two studies have shown benefit from prophylactic salpingo-oophorectomy; $0-0.006 \%$ of the operated women developed ovarian/peritoneal cancer compared to $3.7-5 \%$ in the non-operated group [22, 23]. Considering the uncertain benefit of gynaecological screening and lack of an existing consensus regarding the efficacy gynaecological surveillance, our finding of a high proportion of ovarian cancer with an onset before the age of 40 years when reproduction might not yet be completed adds further dilemma to ongoing discussions about surveillance and the timing of preventive salpingo-oophorectomy in women before menopause.

\section{Urinary tract cancer}

In addition, females with Lynch syndrome as well as $\mathrm{MSH} 2$ carriers had an increased proportion of urinary tract, the latter in line with other studies $[2,5,7,16,24]$.
Regarding urinary tract cancer (including renal pelvis, urothelial and bladder cancer but excluding prostate cancer), other studies have indicated a cumulative risk of $2-12 \%$ up to 70 years of age overall, with the highest risk (7-28\%) in men with pathogenic $\mathrm{MSH} 2$ variants [7, 16, 24-26]. An interesting finding by Watson and co-workers (2008) was the observation of increased incidence rates of urinary tract cancer in Danish and Finnish LS families in comparison to LS families from the Netherlands and USA [16], suggesting geographical differences. In our study, we only noted an increased proportion of urinary tract cancer in female Lynch syndrome carriers in the whole group, whereas for male carriers, only those with proven pathogenic MMR variants had an increased frequency, suggesting that this discrepancy is likely due to the limited numbers of affected in the study, although a regional effect 
Table 7 Observed cancer cases for the MSH2 cohort with 100\% or 50\% probability of MMR mutation (excluding colorectal and endometrial cancer)

\begin{tabular}{|c|c|c|c|c|c|c|c|}
\hline Primary site & $\begin{array}{l}\text { Observed } \\
\text { number }\end{array}$ & $\begin{array}{l}\text { Proportion } \\
{[\%]}\end{array}$ & $\begin{array}{l}\mathrm{LL} \\
95 \%\end{array}$ & $\begin{array}{l}U L \\
95 \%\end{array}$ & $\begin{array}{l}\text { Proportion [\%] in Sweden } \\
1970\end{array}$ & $\begin{array}{l}\text { Proportion [\%] in Sweden } \\
2010\end{array}$ & $\begin{array}{l}\text { Reference } \\
\text { outside C }\end{array}$ \\
\hline $\begin{array}{l}\text { Kidney/urinary tract excl } \\
\text { prostate }\end{array}$ & 47 & 21.56 & 16.06 & 27.06 & 8.93 & 5.87 & above \\
\hline Stomach & 30 & 13.76 & 9.17 & 18.35 & 6.44 & 1.41 & above \\
\hline Skin excl melanoma & 24 & 11.01 & 6.88 & 15.14 & 1.87 & 4.54 & above \\
\hline Ovary and Fallopian tube & 20 & 9.17 & 5.5 & 13.3 & 4.86 & 1.92 & above \\
\hline Prostate & 17 & 7.8 & 4.59 & 11.47 & 5.26 & 13.07 & No \\
\hline Breast & 15 & 6.88 & 3.67 & 10.55 & 16.64 & 23.03 & below \\
\hline Brain and nervous system & 12 & 5.5 & 2.75 & 8.72 & 6.19 & 5.13 & No \\
\hline Cervix & 11 & 5.05 & 2.29 & 8.26 & 5.86 & 2.08 & No \\
\hline Small bowel & 8 & 3.67 & 1.38 & 6.42 & 0.54 & 0.56 & above \\
\hline Blood and lymphatic tissue & 8 & 3.67 & 1.38 & 6.42 & 9.98 & 9.29 & below \\
\hline Malignant melanoma & 6 & 2.75 & 0.92 & 5.05 & 4.51 & 9.58 & No \\
\hline Pancreas & 4 & 1.83 & 0.46 & 3.67 & 2.81 & 1.63 & No \\
\hline Lung and airways & 4 & 1.83 & 0.46 & 3.67 & 7.12 & 5.49 & below \\
\hline Liver and biliary system & 3 & 1.38 & 0 & 3.21 & 2.57 & 1.65 & No \\
\hline Thyroid & 3 & 1.38 & 0 & 3.21 & 1.63 & 2.02 & No \\
\hline Oesophagus & 2 & 0.92 & 0 & 2.29 & 0.76 & 0.62 & No \\
\hline Bone and soft tissue & 2 & 0.92 & 0 & 2.29 & 1.59 & 1.07 & No \\
\hline Testicle & 1 & 0.46 & 0 & 1.38 & 1.63 & 3.12 & below \\
\hline Penis & 1 & 0.46 & 0 & 1.38 & 0.34 & 0.18 & No \\
\hline Head and neck & 0 & 0 & 0 & 0 & 3.67 & 2.97 & below \\
\hline Female genital organ & 0 & 0 & 0 & 0 & 0.48 & 0.3 & below \\
\hline Eye & 0 & 0 & 0 & 0 & 0.46 & 0.34 & below \\
\hline Endocrine cancer & 0 & 0 & 0 & 0 & 2.5 & 1.99 & below \\
\hline Unspecified location & 0 & 0 & 0 & 0 & 3.34 & 2.13 & below \\
\hline
\end{tabular}

The observed proportions adjusted for age and sex are compared to those of the general population in year 1970 and 2010 (ref National Board of Health and Welfare). If the observed confidence interval in the Lynch syndrome group did not overlap with the proportions in the general population, the reference is denoted as "above" the reference and is marked in bold

LL Lower level of $95 \%$ confidence interval, UL upper level of $95 \%$ confidence interval

cannot be excluded. Both sexes showed a similar proportion with an age of onset before 50 years for urinary tract cancer (Table 9). Most urinary tract cancers occurred as isolated single cases within families as previously noted [25]. The increased proportion of urinary tract cancer raises questions about possible surveillance for this diagnosis in LS families. However, as of today no consensus exists regarding the benefit, appropriate procedures or intensity of surveillance programs [26, 27]. The Mallorca group in their update of guidelines 2013 for clinical management of LS does not recommend any surveillance for this cancer type except in clinical trials [15].

\section{Non-melanoma skin cancer}

Interestingly, female Lynch syndrome carriers had an increased proportion of non-melanoma skin cancer, also evident in the MSH2 carrier group. This is an interesting finding that needs corroboration in other studies. Of note, our diagnosis includes all malignant tumours - including sebaceous carcinoma, but not sebaceous adenoma which is known to be associated with a variant of Lynch syndrome called Muir-Torre syndrome [28]. The incidence of skin cancer, both melanoma and non-melanoma, is increasing in northern Europe and Sweden but this increase is for both sexes in general population. Our finding showing increased numbers for non-melanoma skin cancer in a sex-dependent way could partly mirror an altered lifestyle, a changing landscape of malignancies in the Lynch population or be the result of other yet undefined causes. A prospective study of subsequent cancers in LS patients suggested an increase in skin cancer with age, which would support this hypothesis, but the results were difficult to interpret as skin cancer may be underreported [29]. 
Table 8 Number and proportion (\%) of Swedish Lynch syndrome family members with onset of primary cancer $<50$ years age in relation to gender and MMR gene mutation

\begin{tabular}{llllllll}
\hline & CRC & EC & OVC & UTC & GC & SB & NMS \\
& No. (\%) & No (\%) & No. (\%) & No. (\%) & No. (\%) & No. (\%) & No. (\%) \\
\hline Male & $203(54)$ & NA & NA & $8(27)$ & $7(22)$ & $3(38)$ & $5(42)$ \\
Female & $139(51)$ & $92(45)$ & $28(64)$ & $9(26)$ & $7(27)$ & $2(25)$ & $1(6)$ \\
MLH1 & $192(62)$ & $33(50)$ & $5(63)$ & $3(19)$ & $5(25)$ & $2(25)$ & $1(13)$ \\
MSH2 & $119(54)$ & $50(59)$ & $16(80)$ & $14(34)$ & $6(20)$ & $3(39)$ & $5(27)$ \\
MSH6 & $23(26)$ & $9(19)$ & $6(42)$ & - & $4(67)$ & - & - \\
PMS2 & $8(30)$ & - & - & - & - & - & -
\end{tabular}

Calculation based on the group of patients with verified age at diagnosis and not on the entire cohort

CRC Colorectal cancer, EC Endometrial cancer, OC Ovarian cancer, UTC Urinary tract cancer (excluding prostate cancer), GC Gastric cancer, SB Small bowel cancer, NMS non-melanoma skin cancer

\section{Pancreatic cancer}

There has been some controversy about including pancreatic cancer in the LS-associated cancer spectrum. Two prospective studies $[29,30]$ and one retrospective study [31] indicated that LS family members had an increased susceptibility for pancreatic cancer. In our cohort, pancreatic cancer showed a relative increase in MLH1 carriers only, in line with the most recent prospective study showing a cumulative risk of $6.2 \%$ for pancreas cancer in $M L H 1$ carriers only [7]. This finding needs further validation in larger studies. Since no family in our cohort had more than one case of pancreatic cancer there is probably no value of screening for pancreatic cancer in families with Lynch syndrome.

\section{Prostate and breast cancer}

Prostate and breast cancer were common in male and female Lynch syndrome carriers respectively, but the

Table 9 Observed cancer cases for the MSH6 cohort with 100\% or 50\% probability of MMR mutation (excluding colorectal and endometrial cancer)

\begin{tabular}{|c|c|c|c|c|c|c|c|}
\hline Primary cancer & $\begin{array}{l}\text { Observed } \\
\text { number }\end{array}$ & $\begin{array}{l}\text { Proportion } \\
{[\%]}\end{array}$ & $\begin{array}{l}\mathrm{LL} \\
95 \%\end{array}$ & $\begin{array}{l}\text { UL } \\
95 \%\end{array}$ & $\begin{array}{l}\text { Proportion [\%] } \\
\text { in Sweden } 1970\end{array}$ & $\begin{array}{l}\text { Proportion [\%] } \\
\text { in Sweden } 2010\end{array}$ & $\begin{array}{l}\text { Reference } \\
\text { outside Cl }\end{array}$ \\
\hline Breast & 16 & 17.78 & 10 & 25.56 & 21.31 & 29.43 & No \\
\hline Ovary and Fallopian tube & 14 & 15.56 & 8.89 & 23.33 & 6.4 & 2.6 & above \\
\hline Prostate & 13 & 14.44 & 7.78 & 22.22 & 5.5 & 11.58 & No \\
\hline Kidney/urinary tract excl prostate & 10 & 11.11 & 5.56 & 17.78 & 8.24 & 5.57 & No \\
\hline Stomach & 8 & 8.89 & 3.33 & 15.56 & 6.74 & 1.38 & No \\
\hline Brain and nervous system & 8 & 8.89 & 3.33 & 15.56 & 4.88 & 4.16 & No \\
\hline Blood and lymphatic tissue & 7 & 7.78 & 2.22 & 13.33 & 8.66 & 8.21 & No \\
\hline Cervix & 4 & 4.44 & 1.11 & 8.89 & 5.93 & 1.79 & No \\
\hline Liver and biliary system & 3 & 3.33 & 0 & 7.78 & 3.14 & 1.71 & No \\
\hline Pancreas & 2 & 2.22 & 0 & 5.56 & 3.23 & 1.85 & No \\
\hline Lung and airways & 2 & 2.22 & 0 & 5.56 & 6.49 & 7 & below \\
\hline Skin excl melanom & 1 & 1.11 & 0 & 3.33 & 1.96 & 5.44 & No \\
\hline Endocrine cancer & 1 & 1.11 & 0 & 3.33 & 2.17 & 1.81 & No \\
\hline Bone and soft tissue & 1 & 1.11 & 0 & 3.33 & 1.24 & 0.83 & No \\
\hline Head and neck & 0 & 0 & 0 & 0 & 2.94 & 2.55 & below \\
\hline Oesophagus & 0 & 0 & 0 & 0 & 0.75 & 0.54 & below \\
\hline Small bowel & 0 & 0 & 0 & 0 & 0.5 & 0.56 & below \\
\hline female genital organ & 0 & 0 & 0 & 0 & 0.72 & 0.46 & below \\
\hline Testicle & 0 & 0 & 0 & 0 & 0.49 & 0.9 & below \\
\hline Penis & 0 & 0 & 0 & 0 & 0.18 & 0.11 & below \\
\hline Malign melanom & 0 & 0 & 0 & 0 & 3 & 7.23 & below \\
\hline Eye & 0 & 0 & 0 & 0 & 0.47 & 0.34 & below \\
\hline Thyroid & 0 & 0 & 0 & 0 & 1.35 & 1.59 & below \\
\hline Unspecified location & 0 & 0 & 0 & 0 & 3.72 & 2.37 & below \\
\hline
\end{tabular}

The observed proportions adjusted for age and sex are compared to those of the general population in year 1970 and 2010 (ref National Board of Health and Welfare). If the observed confidence interval in the Lynch syndrome group did not overlap with the proportions in the general population, the reference is denoted as "above" the reference and is marked in bold 
proportion was not elevated compared to the general population, indeed, the proportion of breast cancer was lower than expected among our Lynch syndrome cohort.

At present, neither prostate cancer nor breast cancer is considered part of the tumour spectrum in LS but a possible role for both cancers in LS is under debate. Previous studies evaluating the risk for breast cancer in LS have had conflicting results and only few have included all four MMR genes. In a recent study by Möller et al., the risk for breast cancer in patients with LS is not significantly increased, which is in line with our results [7]. One explanation to the lower than expected proportion of breast cancer in our cohort might be that the prevalence of Lynch syndrome related tumours is high reducing the relative contribution of breast cancer in our cohort. In addition, breast cancer is common in the general population and has a later age of onset compared to most LS associated cancers. Thus, in former generations when LS patients often died from their first cancer, breast cancer was not as common. For prostate cancer, the proportion in our cohort did not show any tendency towards higher values than the general population, a result that was unchanged even after stratifying the cohort for different MMR genes. An increased incidence of prostate cancer among LS patients has been suggested, but also here different studies present conflicting results. Möller et al. 2018 reports an increased incidence of prostate cancer in a prospective dataset of patients with MSH2 pathogenic variants, with a later age at onset that other LS associated cancers [7]. As early detection of invasive colorectal cancer is associated with a very high survival today, patients are more likely to develop prostate cancer later in life, as opposed to former generations. With our retrospective design this might affect the results, given that the prevalence of prostate cancer is high in Sweden and a potential increased risk is likely to be modest and occur at an older age.

\section{Limitations and strengths}

Our material is based on recruitment of patients with colon cancer and/or endometrial cancer, through the Swedish Departments of Oncogenetics and usually there is early onset of cancer or clustering of several cancer diagnoses in the family. This may have led to selection bias, e.g. cases with pathogenic MMR variants of low penetrance (most likely those with MSH6 or PMS2 variants) will be missed. Inaccessibility to older medical reports was another concern, preventing the verification of cancer diagnosis in around $10 \%$ of the older generations in our study cohort. The retrospective nature of our study and the paucity of individuals with pathogenic variants in PMS2 and MSH6 necessitated wide confidence intervals that may have led to an underestimation of cancer types in these two groups. In addition, in former generations LS patients often died from their first cancer, as opposed to today when most LS patients under surveillance survive their first as well as subsequent cancers and thus may develop other late-onset tumours not seen in previous generations. This may bias our results.

The study has the benefit of being almost nationwide covering a population of around 8.3 million (83\% of country's population). In addition, pedigrees were comparably vast, containing at least three consecutive generations. Furthermore, the size of our cohort is not negligible covering a total of 1053 LS patients with cancer. Another strength of our study was the confirmation of clinical data (i.e., cancer diagnoses and age at onset) in $90 \%$ of our LS cohort through the Swedish cancer registry.

\section{Conclusion}

In summary, the tumour spectrum of Swedish Lynch syndrome patients overlaps with that of LS patients in other Western countries. In addition to the increased risk of colon and endometrial cancer, $\mathrm{MSH} 2$ carriers develop multiple other cancers including gastric, urinary tract, ovarian, small bowel and non-melanoma skin cancer. In contrast, $\mathrm{MLH1}$ carriers show an increased proportion of gastrointestinal cancers and MSH6 carriers of ovarian cancer. In addition, gender affected the tumour spectrum, with non-melanoma skin cancer noted in women only. The tumour spectrum also varies between genders and as over time, demonstrating the importance of not only genetic but also environmental factors in determining cancer predisposition. Our results may contribute to more accurate cancer risk estimations in Lynch syndrome patients thus providing better evidence upon which to base surveillance recommendations.

\section{Acknowledgements \\ None.}

\section{Funding}

This study has not received any funding.

Availability of data and materials

Please contact author for data requests.

\section{Authors' contributions}

CA, GS, IH, SGM, MSA collected all the pedigree data containing relationships, cancer diagnoses and year of diagnosis from the four other sites in Sweden and updated it with additional information. JVS, AL, EB, KLR collected the pedigree data from Stockholm and updated it. MK, JvS, AL and ET analysed the tumour data and the results of the statistical analysis. JVS, MK, JEF, AL and ET participated in the study design and coordination. JVS, $M K, E B, A L$ and $E T$ wrote the manuscript. All authors read and approved the final manuscript.

\section{Authors' information}

None. 


\section{Ethics approval and consent to participate}

The study was approved by the Regional Ethical Review Board in Stockholm, Sweden. Diary number 2002-241 and Diary number 2014-1320-31.

\section{Consent for publication}

Not applicable.

\section{Competing interests}

The authors declare that they have no competing interests.

\section{Publisher's Note}

Springer Nature remains neutral with regard to jurisdictional claims in published maps and institutional affiliations.

\begin{abstract}
Author details
${ }^{1}$ Department of Oncology, Karolinska University Hospital, Stockholm, Sweden. ${ }^{2}$ Department of Clinical Genetics, Karolinska University Hospital, Solna, 17176 Stockholm, Sweden. ${ }^{3}$ Department of Molecular Medicine and Surgery, Karolinska Institutet, Stockholm, Sweden. ${ }^{4}$ Department of Clinical Genetics, Akademiska University Hospital, Uppsala, Sweden. ${ }^{5}$ Department of Clinical Genetics, Norrlands University Hospital, Umeå, Sweden. ${ }^{6}$ Department of Clinical Genetics, Linköpings University Hospital, Linköping, Sweden. 7 Division of Clinical Genetics, Department of Laboratory Medicine, Lund University, Lund, Sweden. ${ }^{8}$ Department of Clinical Genetics, Office for Medical Services, Division of Laboratory Medicine, Lund, Sweden.
\end{abstract}

Received: 27 July 2018 Accepted: 9 October 2018

Published online: 23 October 2018

\section{References}

1. Lynch HT, Watson P, Shaw TG, Lynch JF, Harty AE, Franklin BA, et al. Clinical impact of molecular genetic diagnosis, genetic counseling, and management of hereditary cancer. Part II: hereditary nonpolyposis colorectal carcinoma as a model. Cancer. 1999;86(11 Suppl):2457-63.

2. Aarnio M, Sankila R, Pukkala E, Salovaara R, Aaltonen LA, de la Chapelle A, et al. Cancer risk in mutation carriers of DNA-mismatch-repair genes. Int J Cancer. 1999;81(2):214-8.

3. Barrow E, Robinson L, Alduaij W, Shenton A, Clancy T, Lalloo F, et al. Cumulative lifetime incidence of extracolonic cancers in lynch syndrome: a report of 121 families with proven mutations. Clin Genet. 2009;75(2):141-9.

4. Bonadona V, Bonaiti B, Olschwang S, Grandjouan S, Huiart L, Longy M, et al. Cancer risks associated with germline mutations in $\mathrm{MLH1}, \mathrm{MSH} 2$, and MSH6 genes in lynch syndrome. Jama. 2011;305(22):2304-10.

5. Engel C, Loeffler M, Steinke V, Rahner N, Holinski-Feder E, Dietmaier W, et al. Risks of less common cancers in proven mutation carriers with lynch syndrome. J Clin Oncol. 2012;30(35):4409-15.

6. Lynch HT, de la Chapelle A. Hereditary colorectal cancer. N Engl J Med. 2003;348(10):919-32.

7. Moller P, Seppala TT, Bernstein I, Holinski-Feder E, Sala P, Gareth Evans D, et al. Cancer risk and survival in path_MMR carriers by gene and gender up to 75 years of age: a report from the prospective lynch syndrome database. Gut. 2018;67(7):1306-16.

8. Moller P, Seppala T, Bernstein I, Holinski-Feder E, Sala P, Evans DG, et al. Cancer incidence and survival in lynch syndrome patients receiving colonoscopic and gynaecological surveillance: first report from the prospective lynch syndrome database. Gut. 2017;66(3):464-72.

9. Rodriguez-Bigas MA, Boland CR, Hamilton SR, Henson DE, Jass JR, Khan PM, et al. A National Cancer Institute workshop on hereditary nonpolyposis colorectal Cancer syndrome: meeting highlights and Bethesda guidelines. J Natl Cancer Inst. 1997:89(23):1758-62.

10. Vasen HF, Watson P, Mecklin JP, Lynch HT. New clinical criteria for hereditary nonpolyposis colorectal cancer (HNPCC, lynch syndrome) proposed by the international collaborative group on HNPCC. Gastroenterology. 1999;116(6):1453-6.

11. Mecklin JP, Aarnio M, Laara E, Kairaluoma MV, Pylvanainen K, Peltomaki $P$, et al. Development of colorectal tumors in colonoscopic surveillance in lynch syndrome. Gastroenterology. 2007:133(4):1093-8.

12. Tzortzatos G, Wersall O, Danielsson KG, Lindblom A, Tham E, Mints M. Familial cancer among consecutive uterine cancer patients in Sweden. Hered Cancer Clin Pract. 2014;12(1):14.
13. Lagerstedt-Robinson K, Rohlin A, Aravidis C, Melin B, Nordling M, StenmarkAskmalm M, et al. Mismatch repair gene mutation spectrum in the Swedish lynch syndrome population. Oncol Rep. 2016;36(5):2823-35.

14. Haanstra JF, Al-Toma A, Dekker E, Vanhoutvin S, Nagengast FM, MathusVliegen EM, et al. Incidence of small bowel neoplasia in lynch syndrome assessed by video capsule endoscopy. Endosc Int Open. 2017;5(7):E622e626.

15. Vasen HF, Blanco I, Aktan-Collan K, Gopie JP, Alonso A, Aretz S, et al. Revised guidelines for the clinical management of lynch syndrome (HNPCC): recommendations by a group of European experts. Gut. 2013;62(6):812-23.

16. Watson P, Vasen HFA, Mecklin JP, Bernstein I, Aarnio M, Jarvinen HJ, et al. The risk of extra-colonic, extra-endometrial cancer in the lynch syndrome. Int J Cancer. 2008;123(2):444-9.

17. Helder-Woolderink JM, Blok EA, Vasen HF, Hollema H, Mourits MJ, De Bock $\mathrm{GH}$. Ovarian cancer in lynch syndrome; a systematic review. Eur J Cancer. 2016;55:65-73.

18. Dove-Edwin I, Boks D, Goff S, Kenter GG, Carpenter R, Vasen HF, et al. The outcome of endometrial carcinoma surveillance by ultrasound scan in women at risk of hereditary nonpolyposis colorectal carcinoma and familial colorectal carcinoma. Cancer. 2002;94(6):1708-12.

19. Offit K, Kauff ND. Reducing the risk of gynecologic cancer in the lynch syndrome. N Engl J Med. 2006:354(3):293-5.

20. Renkonen-Sinisalo L, Butzow R, Leminen A, Lehtovirta P, Mecklin JP, Jarvinen HJ. Surveillance for endometrial cancer in hereditary nonpolyposis colorectal cancer syndrome. Int J Cancer. 2007;120(4):821-4.

21. Tzortzatos G, Andersson E, Soller M, Askmalm MS, Zagoras T, GeorgiiHemming $P$, et al. The gynecological surveillance of women with lynch syndrome in Sweden. Gynecol Oncol. 2015;138(3):717-22.

22. Chen LM, Yang KY, Little SE, Cheung MK, Caughey AB. Gynecologic cancer prevention in lynch syndrome/hereditary nonpolyposis colorectal cancer families. Obstet Gynecol. 2007;110(1):18-25.

23. Schmeler KM, Lynch HT, Chen LM, Munsell MF, Soliman PT, Clark MB, et al. Prophylactic surgery to reduce the risk of gynecologic cancers in the lynch syndrome. N Engl J Med. 2006;354(3):261-9.

24. Skeldon SC, Semotiuk K, Aronson M, Holter S, Gallinger S, Pollett A, et al. Patients with lynch syndrome mismatch repair gene mutations are at higher risk for not only upper tract urothelial cancer but also bladder cancer. Eur Urol. 2013;63(2):379-85.

25. Joost $P$, Therkildsen $C$, Dominguez-Valentin $M$, Jonsson M, Nilbert M. Urinary tract Cancer in lynch syndrome; increased risk in carriers of $\mathrm{MSH} 2$ mutations. Urology. 2015;86(6):1212-7.

26. van der Post RS, Kiemeney LA, Ligtenberg MJ, Witjes JA, Hulsbergen-van de Kaa CA, Bodmer D, et al. Risk of urothelial bladder cancer in lynch syndrome is increased, in particular among MSH2 mutation carriers. J Med Genet. 2010;47(7):464-70.

27. Bernstein IT, Myrhoj T. Surveillance for urinary tract cancer in lynch syndrome. Familial Cancer. 2013;12(2):279-84.

28. South CD, Hampel H, Comeras I, Westman JA, Frankel WL, de la Chapelle A. The frequency of Muir-Torre syndrome among lynch syndrome families. J Natl Cancer Inst. 2008;100(4):277-81.

29. Moller P, Seppala T, Bernstein I, Holinski-Feder E, Sala P, Evans DG, et al. Incidence of and survival after subsequent cancers in carriers of pathogenic MMR variants with previous cancer: a report from the prospective lynch syndrome database. Gut. 2017;66(9):1657-64.

30. Win AK, Young JP, Lindor NM, Tucker KM, Ahnen DJ, Young GP, et al. Colorectal and other cancer risks for carriers and noncarriers from families with a DNA mismatch repair gene mutation: a prospective cohort study. J Clin Oncol. 2012;30(9):958-64.

31. Kastrinos F, Mukherjee B, Tayob N, Wang F, Sparr J, Raymond VM, et al. Risk of pancreatic cancer in families with lynch syndrome. Jama. 2009;302(16): $1790-5$ 